\title{
XXXII. Mineralogical and chemical examination of hyalosiderite, a new mineral
}

\section{Dr. Walchner}

To cite this article: Dr. Walchner (1824) XXXII. Mineralogical and chemical examination of hyalosiderite, a new mineral , Philosophical Magazine Series 1, 63:311, 181-190, DOI: $10.1080 / 14786442408644490$

To link to this article: http://dx.doi.org/10.1080/14786442408644490

里 Published online: 29 Jul 2009.

Submit your article to this journal $[\pi$

Џ Article views: 2

Q View related articles $₫$ 
length may consult the Monatliche Correspondenz by Baron Zach, vol. xvii. xxiv. and xxvi.; where he will find formulæ adapted, by $M$. Bessel, to almost every case that can arise in practice. See also Santini's Elementi di Astronomia, vol. i. page 261 .

Although I have, in this communication, alluded only to the immersion and emersion of the bodies with respect to the inner circumference of the ring, yet it is evident that the same principles may be applied to the immersion and emersion of the bodies with respect to the outer circumference of the ring, at $\pi, \sigma$, and $\pi^{\prime}, \sigma^{\prime}$, respectively. And these double observations will tend to ensure greater accuracy. M. Frauenhofer however considers that the edge of the inner circle is more perfect than that of the outer one.

It must be evident that the correctness of any results, deduced from a micrometer of this kind, will depend on the accuracy with which the circles are turned and finished. In this respect M. Frauenhofer's micrometer seems as perfect as human skill can make it: and it certainly does credit to the talents of this distinguished artist.

XXXII. Mineralogical and Chemical Examination of Hyalosiderite, a new Mineral. By Dr. WALcinen, of Freiburg in the Breisgau.* (With a Plate of Crystals.)

\section{Mineralogical Description.}

\section{$\oint 1$.}

THE mineral, of which I now communicate an examination, is found on the Kaiserstuhl in the Breisgau, a rock belonging to the trap formation, in the neighbourhood of the village Sasbach, in a basaltic anygdaloid, of a reddish and liver-brown colour, accompanied with augite and bitter spar.

I found it so long ago as the year 1819 , when on a mineralogical excursion which I undertook upon this interesting mountain. The opinions concerning it were very various: sometimes it was declared to be olivine, and sometimes it was pronounced to be augite. Both assertions appeared to me improbable, and I felt inclined to look upon it as a mineral hitherto unknown. A more particular examination of its form and composition strengthened my opinion. At Gottingen, where I afterwards continued my studies, I resumed my investigation of the subject, and communicated the re-

* From Schweigger's Neues Journal für Chemie, \&c. band ix. p. 65. 


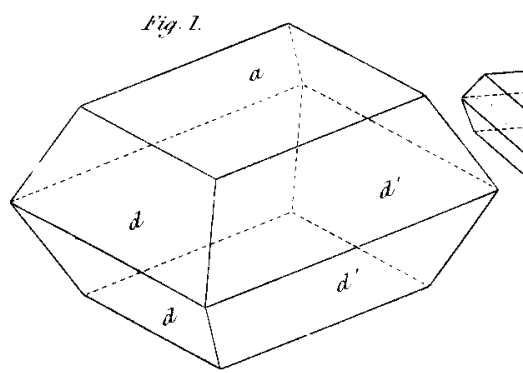

$F i g$.
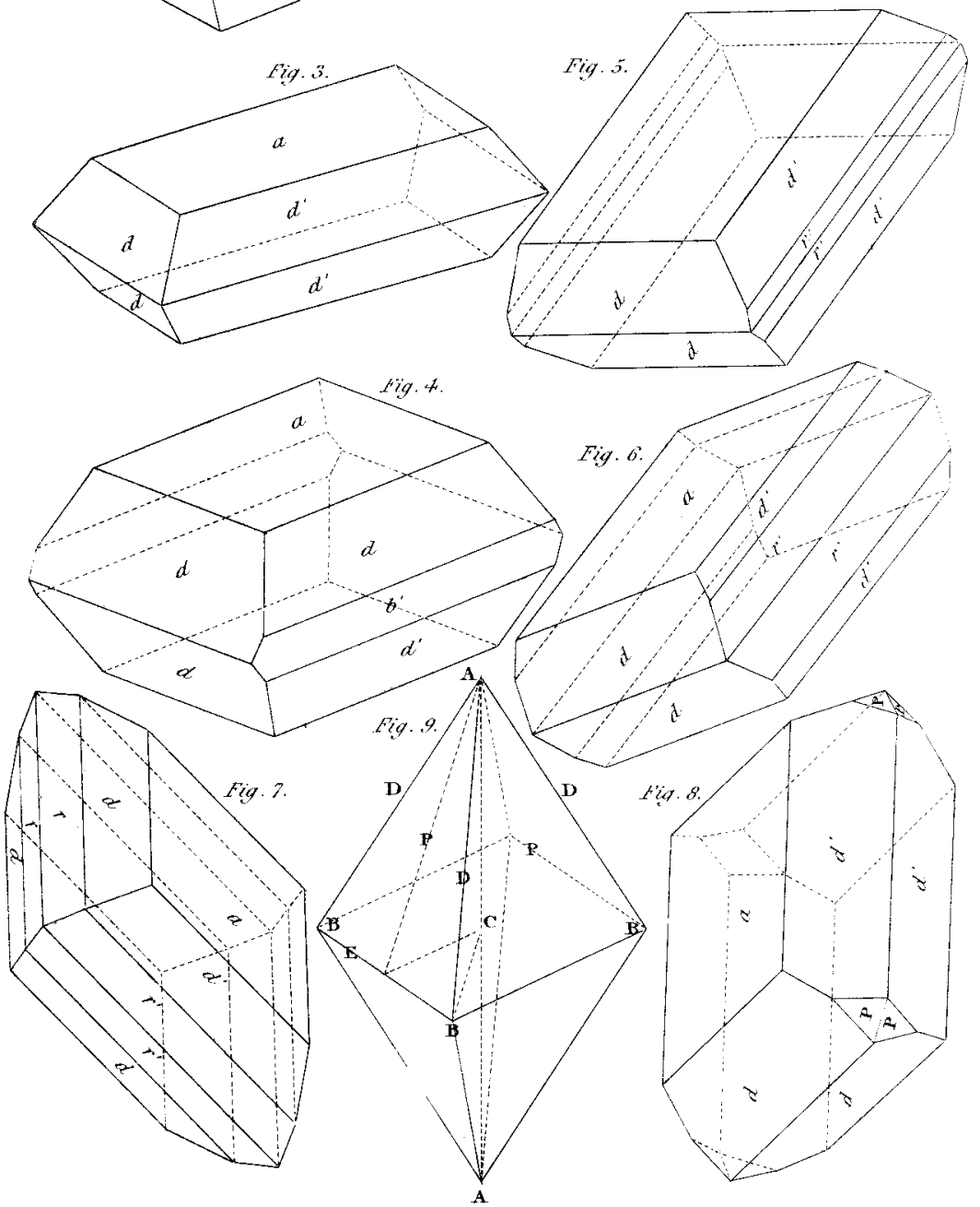

5. Thenter he 
sults of it, together with the mineral, to my honoured teacher M. Hausmann; who acknowledged it to be a new mineral, and was so good as to direct my attention to the analogy between it and crystallized iron slag.

\section{$\S 2$.}

Hyalosiderite occurs for the most part in crystals; but likewise in small blunt-edged, friable, loosely coherent grains. The crystalline forms hitherto observed in it are the following:

(1.) The rectangular octahedron, having its terminal solid angles replaced by tangent planes (fig. 1).

This form varies,

a.) By the different proportions of the terminal planes to those of the octahedron. 'The former are sometimes so large in proportion to the latter, that the crystallization acquires the appearance of a rectangular four-sided tablet bevelled on each side (fig. 2).

b.) By the elongation in either direction of the edges of the base, which is sometimes so considerable, that the form becomes prismatic (fig. 3).

(2.) The same crystallization (1) with the greater edges of the base replaced by tangent planes, those planes generally small (fig. 4).

(3.) The same crystallization (1), with the greater edges of the base replaced by two planes. The size of the new planes varies in proportion to that of the others. They are sometimes small (fig. 5), and sometimes so enlarged that the planes of the octahedron on which they rest almost disappear (fig. 6).

(4.) The same crystallization (1), with the solid angles of the base replaced by two triangular planes, usually very small (fig. 8).

(5.) The same crystallization (1), with all the edges of the base replaced by two planes (fig. 7 ).

Twin crystals I have not met with.

\section{$\S 3$.}

The crystals are very small, scarcely of the size of lentils; they appear when the amygdaloid has become disintegrated, as they resist the action of the elements for a greater length of time; they are either attached to augite, or freely disseminated in the amygdaloid; and are, for the most part, imperfectly formed. Their surface is smooth, and exhibits, in an oblique light, sometimes a brass yellow, or a gold yellow colour, sometimes the colour of tarnished steel; which is owing to a thin coat of perhydrate of iron, investing most of the crystals. Their proper colour is reddish- or yellowish-brown. 
Fracture small conchoidal; external lustre metallic, of the fracture vitreous; hardness, in newly exposed crystals, between that of felspar and that of apatite; cleavage at right angles to the axis of the octahedron $\mathrm{AA}^{\prime}$ (fig. 9), not very perceptible.

Transparent on the thin edges, or in small splinters, with a hyacinth red colour passing into a wine-yellow; the streak of a cinnamon colour. Specific gravity 2.875 ; temp. $70 \cdot 7 \mathrm{~F}$.

Single crystals are sometimes attracted by the magnet; but always after they have been made slightly red hot, by which they are rendered black.

Before the blow-pipe they immediately become black and melt into a globule, which is attracted by the magnet.

With borax they are readily and completely reduced to a transparent glass, which, while hot, has a yellowish-green colour, that almost entirely disappears on cooling, if but little of the mineral has been employed; but if the borax be saturated with it, it becomes black and opake. They are dissolved by salt of phosphorus into a clear greenish glass, leaving a skeleton of silica behind, and the glass after cooling becomes colourless.

If the boracic glass, containing a small portion of the mineral, be cautiously treated with tin, the globule, after it has become quite cold, exhibits a slight but determined beautiful green colour.

\section{$\oint 4$.}

From the nature of the forms above enumerated we may assume, that the system of crystallization of this mineral is a trimetric one *. 'The planes $d$ and $d$, presenting themselves most frequently, and which form the rectangular octahedron, appear then as bounding planes, which truncate rectangularly the edges of the base of the ground form; the planes $a$ as the horizontal, and the planes $\mathbf{P}$ as the primary planes, since the edges, which those planes form with the planes $d^{\prime}$ and $d$, are in parallelism with each other.

\section{$\S 5$.}

The primary planes are too small for the measurement of their mutual inclination. The inclination of the planes $d$ and $d^{\prime}$ may be determined most exactly, although, on account of the smallness of the crystals, even these measurements remain imperfect. The inclination of $d$ on $d^{\prime}$ was determined to be $141^{\circ}$, and the inclination of $d^{\prime}$ on $a$ amounted to rather more than $130^{\circ}$. Now if these measurements are taken as the basis for determining the mathematical character of the primary

* Hausmann Unters. üb. d. Form. d. lebl. Nat. i. p. 417.

form, 
form (fig. 9), then the following proportion of inclination for the base would pretty nearly approach the truth:

$\mathrm{B}^{\prime} \mathrm{E}: \mathrm{EC}: \mathrm{CA}=\sqrt{ } 23: 7: 10$.

The inclination of the primary planes on the principal axis, or the angle $\mathrm{EAC}$, would, according to this proportion, be $=34^{\circ} 59^{\prime} 38^{\prime \prime}$, and the angles of the base $\mathrm{B} \mathrm{B}^{\prime} \mathrm{B}=111^{\circ} 10^{\circ} 6^{\prime \prime}$, and $\mathrm{B}^{\prime} \mathrm{B} \mathrm{B}^{\prime}=68^{\circ} 49^{\prime} 54^{\prime \prime}$.

$\$ 6$.

Besides the primary planes, the bounding planes $A, B^{\prime}, D$, $\mathrm{D}^{\prime}$ occur in the crystals hitherto observed, the inclinations of which may be found immediately from the proportion of inclination on the base. The planes $r^{\prime}$ and $r$, on the contrary, are secondary planes, from the second division of the vertical edge-zones. 'The inclination of the planes $r^{\prime}$ which appertain to the first vertical edge-zone, was ascertained with some exactness. They answer to the secondary proportion $2 \mathrm{CB}^{\prime}$ : $3 \mathrm{CA}$; whence the sign $\mathrm{B}^{\prime} \mathrm{A} \frac{2}{3}$ belongs to them. The planes $r$ probably answer to an analogous secondary proportion in the second vertical edge-zone.

$\S 7$.

The denotation of the different crystalline forms hitherto observed in this mineral would consequently be,

$$
\begin{aligned}
& \text { 1. } 2 \mathrm{~A} \text {. 4 } \mathrm{D}_{d^{\prime}} \text { 4. D. (fig. 1, 2, 3.) } \\
& \text { 2. } 2 \text { A. } 2 \underset{b^{\prime}}{\mathrm{B}^{\prime} .4 \mathrm{D}^{\prime}} \text {. 4. D. (fig. 4.) }
\end{aligned}
$$

3. 2 A. $4 \mathrm{D}^{\prime}$. 4 D. $4 \mathrm{~B}^{\prime} \mathrm{A}$. . (fig. 5, 6.)

$$
\begin{array}{lllll}
a & d^{\prime} & d & r^{\prime}
\end{array}
$$

4. $2 \mathrm{~A} .4 \mathrm{D}^{\prime}$. 4 D. $4 \mathrm{~B}^{\prime} \mathrm{A} \frac{2}{3} \cdot 4 \mathrm{BA} \frac{2}{3}$ ? (fig. 7.)

$$
\begin{array}{llll}
a & d & d & r
\end{array}
$$

5. 8 P. $\underset{a}{2 \mathrm{~A}} \underset{d^{\prime}}{\mathrm{D}}$. $\underset{d}{\mathrm{D}}$. (fig. 8.)

The chief inclinations are,

$$
\begin{array}{lrr}
\text { Pon } \mathrm{P}^{\prime}=110^{\circ} & 0^{\prime} & 44^{\prime \prime} \\
a \ldots d^{\prime}=130 & 18 & 56 \\
a \ldots d=141 & 4 & 54 \\
d^{\prime} \ldots d^{\prime}=99 & 22 & 8 \\
d \ldots d=77 & 50 & 12 \\
d \ldots d & =79 \\
d^{\prime} \ldots b^{\prime}=139 & 41 & 4 \\
r^{\prime} \ldots d=119 & 29 & 47 \\
r^{\prime} \ldots d^{\prime}=169 & 10 & 51 \\
r^{\prime} \ldots r^{\prime}=121 & 0 & 26
\end{array}
$$

$$
\S 8 .
$$

On a comparison of the crystallization of the hyalosiderite 
with the crystals of slags, formed in various metallurgic processes, we find a corresponding similarity not only in the forms in general, but also in the angles of inclination of the planes. The measurement of these angles, which M. Hausmann has given in his Specimen Crystallographice Metallurgica, $\$ 32$, could be but very imperfect on account of their small size. The determinations here communicated, which cannot indeed boast of very great accuracy, will contribute to adjust in some measure the determinations published in that treatise.

The rectangular octahedron described by M. Hausmann (fig. 14, 15, 16) is formed by the planes which are here marked $d$ and $" \prime \prime$; the planes $d$ answer to the planes M, chosen in the definition of that treatise; so that the planes $r^{\prime}$ correspond with the planes P. Later observations have also acquainted us with the planes $d^{\prime}$ in the crystallized slag. The rectangular bases of the rectangular octahedrons in the crystallized slag, namely in that from the copper pyrites smelting works at Lauten (Hausm. Spec. Cryst. Met. fig. 18), answer perfectly to an octahedron formed by the bounding planes $d^{\prime}$ and $d$. The angles which the diagonals of the rectangular bases form with their edges, are similar to the semi-angles of the base of the ground form, consequently $=\angle \mathrm{CB}^{\prime} \mathrm{B}$ and $\angle \mathrm{CBB}^{\prime}$. These angles measure, according to the fundamental proportion of inclination above assumed, $55^{\circ} 35^{\prime} 3^{\prime \prime}$ and $34^{\circ} 24^{\prime} 57^{\prime \prime}$.

\section{Chemical Analysis.}

\section{f 9.}

The hyalosiderite brought to a red-heat, whether in a glass retort or in a platinum crucible, becomes black, but does not yield any perceptible quantity of water; nor is it perceptibly altered in texture or in weight.

Concentrated muriatic acid attacks the mineral even when cold, dissolves it by the aid of a gentle heat, and forms with it, on evaporation, a gelatinous mass, which after desiccation was evidently silica.

a.) A few decigrammes of the powdered mineral were now treated with concentrated muriatic acid, until their solution was completely effected; the solution evaporated to dryness by a gentle heat; the residuum extracted by water, acidulated with the same acid, and separated by a filter. The yellowish fluid thus obtained was mixed with caustic ammonia, which produced a reddish-brown precipitate. This was again dissolved in muriatic acid, in order to ascertain whether mag-

Vol, 63. No. 311. March 1824. A a nesia 
nesia was present, and the solution was carefully neutralized with carbonate of soda. Perhydrate of iron was separated, which was treated with caustic potassa and then separated by filtration from the alkaline fluid, from which muriate of aminonia precipitated a little alumina. The solution, from which iron and argillaceous earth had thus been separated, was mixed, at a boiling heat, with carbonate of soda. 'The copious precipitate thus obtained consisted of magnesia, which, after desiccation and exposure to a red-heat, and re-solution in dilute nitric acid, yielded a little oxide of manganese. The neutralized solution of magnesia in nitric acid became turbid, but in a scarcely perceptible degree, by the addition of oxalate of ammonia.

b.) A second portion of the mineral was treated with muriatic acid, in order to ascertain the alkali which it might contain: the solution was evaporated to dryness, the silica separated in the usual manner, and the fluid remaining after the separation of the silica precipitated with caustic ammonia and with its carbonate. The residuum obtained by evaporation, was ignited in a platinum crucible, in which muriate of potassa remained.

It will be seen from these experiments that the hyalosiderite consists of silica, oxide of iron, magnesia, alumina, oxide of manganese, and potassa.

\section{$\$ 10 . \quad$ A.}

In order to determine the proportions of the constituent parts of this mineral, it was subjected to the following analysis:

a.) 1.040 gramm. of hyalosiderite, reduced to the finest powder, were exposed to a moderate red-heat for about half an hour in a platinum crucible, with three times its weight of anhydrous carbonate of soda. The mixture, after fusion, was of a brownish-yellow colour, and gave, when softened with water and treated with concentrated muriatic acid, a clear yellow solution. By evaporation to dryness \&c. 0.329 of calcined siliceous earth were obtained.

b.) After the separation of the silica, the remaining fluid was accurately neutralized with carbonate of soda. The precipitate thereby occasioned, after having been separated from the fluid, was digested, whilst yet in its moist state, with a solution of caustic potassa, so long as it became diminished in quantity; and the residual iron well dried and calcined gave 0.330 gramm. of peroxide of iron, $=0.309$ protoxide of iron.

$c$.$) The alkaline fluid of (b)$, was now treated with a solution of muriate of ammonia so long as precipitation took place. 
This precipitate, after calcination, amounted to 0.023 gramm. and had the properties of pure alumina.

d.) The fluid (b), from which the iron and argillaceous earth had been precipitated, and which did not become turbid by the addition of oxalate of potassa, was again acidulated, evaporated to the requisite degree, and precipitated at a boiling temperature with carbonate of soda. The precipitate dried and strongly calcined gave 0.277 gramm. of magnesia, which, after being dissolved in dilute nitric acid, left 0.005 of oxide of manganese.

e.) The magnesia still contained in the remaining fluid of (d), after that had been previously neutralized with muriatic acid, and sufficiently concentrated, was precipitated by means of carbonate of ammonia and phosphate of soda; by which 0.164 gramm. of calcined phosphate of magnesia were obtained, which answer to 0.065 gramm of pure magnesia.

B.

In order to determine the proportion of potassa in the hyalosiderite, 0.567 gramm. of the mineral were treated with muriatic acid; the iron, alumina, magnesia, silica, and manganese, separated in the usual manner, the remaining solution evaporated to dryness, and the residuum calcined in a platinum crucible. What remained was dissolved in distilled water, and treated with muriate of platinum, and thus gave 0.055 gramm. of the triple salt $=0.016$ gramm. pure potassa.

$$
\text { C. }
$$

As the relative effect of glass of borax in the treatment with tin seemed to indicate the presence of chrome in this mineral, a quantity of it, exactly weighed, was fused with nitrate of potassa in order to discover that metal. The melted mass was of a yellowish-brown colour with some grass-green streaks which originated from sub-manganesate of potassa. The soluble part was now properly extracted with water, the fluid thus obtained carefully neutralized with nitric acid, and then treated with a solution of protonitrate of mercury, on which a slight reddish turbidness merely took place, so that the quantity of chrome could not be ascertained.

According to this analysis, 1.040 gramm. of hyalosiderite, yield

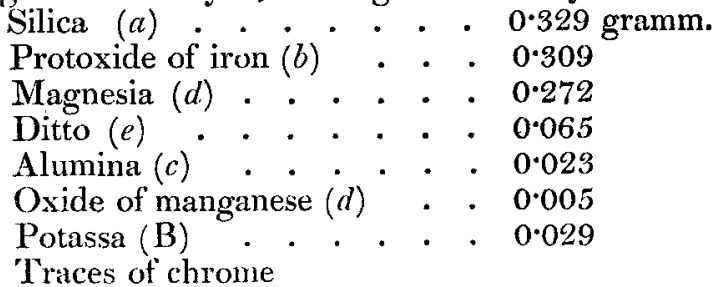

A a 2

$\overline{1 \cdot 032}$ 
100 parts of this mineral therefore contain

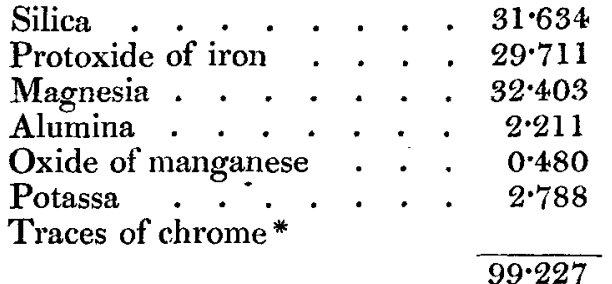

$\S 11$.

Through the kindness of my honoured teachers MM. Hausmann and Stromeyer of Göttingen, I was enabled to submit to a chemical analysis some slags, the mineralogical similarity of which with our mineral has been mentioned above. The same method was followed in the analysis which was observed in that of the hyalosiderite, and I therefore briefly state the results.

$$
\$ 12 .
$$

An iron slag from the iron smelting works near Dax in the Pyrenees, which M. Hausmann has describedt, and which M. Stromeyer kindly presented to me, had the specific gravity of 3.700 at the temperature of $73.4 \mathrm{~F}$. and contained, in 100 parts, Silica . . . . . 32.959

$$
\begin{aligned}
& \text { Protoxide of iron . . } 61.235 \\
& \text { Magnesia . . . . . } 1.896 \\
& \text { Alumina . . . . . } 1 \cdot 560 \\
& \text { Oxide of manganese . . } 1.301 \\
& \text { Potassa . . . . } \frac{0.204}{99 \cdot 155}
\end{aligned}
$$

\section{$\S 13$.}

Another iron slag, from Bodenhausen in the Hartz, which in its external appearance bore the greatest resemblance to our mineral, was kindly presented to me by M. Hausmann. Its specific gravity was 3.529 at the temperature of $70.7 \mathrm{~F}$. and it contained,

$$
\begin{aligned}
& \text { Silica . . . . . } 32 \cdot 346 \\
& \text { Protoxide of iron . . } 62 \cdot 042 \\
& \text { Magnesia . . . 1.404 } \\
& \text { Oxide of manganese . } \quad 2 \cdot 645 \\
& \text { Potassa . . . . } \frac{\mathbf{0 . 2 8 5}}{99 \cdot 746}
\end{aligned}
$$

* My honoured friend Professor Buzengeiger directed my attention to the presence of chrome in this mineral. Chrome has probably been overlooked in many minerals. On a future opportunity I shall have occasion to point out its existence in a mineral long known and frequently analysed.

f Moll's Ephemerides, d. B. u. H. III. 1815, p. 39. ff. 


\section{$\oint 14$.}

A third slag, which had been found many years ago at Lautenthal in the Hartz at copper-works where copper pyrites was smelted, and the crystallization of which has been described above $(\$ 8)$, I likewise obtained through the kindness of M. Hausmann. Its specific gravity at the temperature of $65 \cdot 3 \mathrm{~F}$. was $3 \cdot 870$.

As I had convinced myself by a previous analysis, that it contained copper, I directed through the solution in muriatic acid, after the silica had been separated from it, a current of sulphuretted hydrogen gas, treated the precipitate thus obtained with nitric acid, and then separated the oxide of copper by caustic potassa. The fluid remaining after the separation of the copper, was treated, whilst warm, with nitric acid, and heated for some time, so as to bring the iron to the maximum of oxidation; the analysis was then proceeded with as usual.

This slag from Lautenthal contained

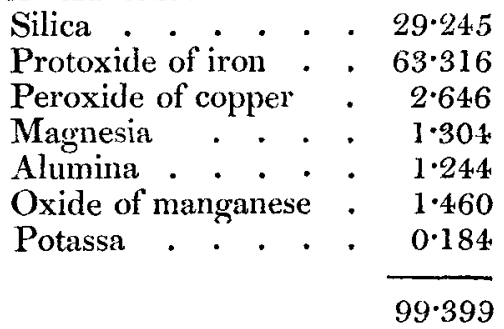

I consider that mineral as a slag likewise which Karsten has described, and which Klaproth analysed, under the name of volcanic iron-glass*. According to Klaproth's analysis, 100 parts of it consist of

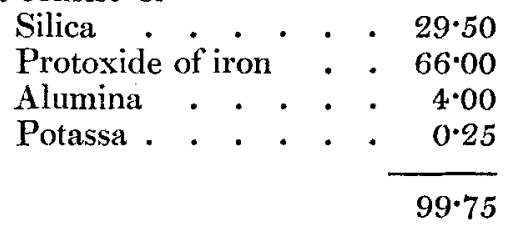

$\oint 16$.

The crystallized slag is consequently a silicate of iron. This in the hyalosiderite appears to be combined with magnesia, which seems to replace the quantity of iron in the slag.

* Beiträge, V. 222 ff. Stromeyer in the Gött gel. Anz. 1810. st. 194. p. 1935. M. Hausmann has given further particulars of it in V. Moll's Jahrb. d. B. u. H. III. 1815. p. 39. ff. 
From the analysis above detailed, it is evident that the mineral from the Kaiserstuhl is actually a new one. The name hyalosiderite has been suggested by its properties and its composition, and is derived from vaios glass, and osingeos iron. The formation of this mineral, it is probable, could not have been the result of operations like those by which the primitive rocks were produced; and we may thence assume, that the rock in which it occurs is of volcanic origin.

XXXIII. On High-pressure Gauges. By Mr. Samuel Seaward.

To the Editors of the Philosophical Magazine and Journal. Gentlemen,

I' $\mathrm{T}$ is highly creditable to the taste of your ingenious correspondent Mr. H. Russell, that he can extract so much amusement from the manufacturing of high-pressure gauges. I hope no one will be so selfish as to envy him the recreation of this harmless pursuit, more especially as he appears very prudently to confine his views to his own individual gratification.

Complexity in a machine or instrument should certainly be as much as possible avoided; but if all instruments are to be condemned which have a diversity of parts (which I understand by the term complex), we should never have enjoyed the benefits of a clock, a loom, or a steam-engine.

My idea of a high-pressure gauge is, that it should be useful; but if it is intended to be merely an amusing toy, why then I should commend Mr. Russell's choice of what he lauds so much as being simple and easy.

The instrument described by your correspondent in the last Number of your Magazine, is substantially the same as the common gauge which has been in use a long time past at the Portable Gas Works, where its defective and uncertain operation has been long known,-practically known in the way of business, not speculatively conjectured: in confirmation of which I beg to state, that the superintendants of that establishment were lately in serious contemplation of erecting a gange 70 feet long, in order that the divisions of the scale might be of arlequate length. This simple fact is, I think, a complete answer to Mr. Russell's crudities.

$\mathrm{Mr}$. R. seems to entertain great fear of its being practicable to make a "tight joint between the glass tube and metal box." 